\title{
Educación para la paz: una reflexión desde Tomás de Aquino
}

\section{Diego Fernando Barrios-Andrade}

https://orcid.org/0ooo-0o01-8979-270X

Universidad Santo Tomás, Colombia

diego.barrios@usantoto.edu.co

\section{Resumen}

Este artículo trata el tema de la educación para la paz siguiendo algunas aportaciones teóricas de Tomás de Aquino en su Suma Teológica. Los objetivos son, por un lado, redefinir la paz desde una perspectiva filosófica y, por otro, elaborar una concepción tomista de la educación para la paz. El método empleado es de corte analitico-interpretativo consistente en revisar ordenadamente ciertos pasajes de la Suma Teológica integrándolos en una argumentación original. La virtud va a ser el término clave desde el cual articular las principales reflexiones de este escrito, pues establece un vinculo entre las nociones de paz y educación, al tiempo que posibilita una comprensión distinta de la educación para la paz. Ello se debe a que la paz, en el pensamiento de santo Tomás, se refiere a un orden entre las facultades humanas y las relaciones interpersonales, que existen solo con dependencia de la virtud. Igualmente, la definición de educación tiene una referencia directa a la virtud, en la que consiste la perfección humana a la que el hombre está destinado conforme a su naturaleza espiritual. Como conclusión, se afirma que la educación para la paz exige un enlace íntimo con la virtud, perspectiva que permite un rediseño teórico de la educación para la paz; en esta línea, de modo operativo, se propone la virtud ética de la humildad como vía de construcción de paz en la escuela.

\section{Palabras clave (Fuente: tesauro de la Unesco)}

Docente; educación para la paz; práctica pedagógica; santo Tomás de Aquino; teoría de la educación; virtudes éticas.

Recepción: 04/12/2020 | Envío a pares: 24/06/2021 | Aceptación por pares: 10/08/2021 | Aprobación: 19/08/2021 


\title{
Peace Education: A Reflection from Thomas Aquinas
}

\begin{abstract}
This article deals with peace education, following some theoretical contributions in Thomas Aquinas's Summa Theologiae. On the one hand, it aims to redefine peace from a philosophical perspective and, on the other, to develop a Thomistic conception of peace education. The method used is analytical-interpretive, consisting of an orderly review of specific passages of Summa Theologiae to integrate them into an original argument. Virtue will be the key term to bring together the primary reflections of this writing since it establishes a link between the notions of peace and education while enabling a different understanding of peace education. In Saint Thomas's thought, peace refers to order between human powers and interpersonal relationships, which exist because of virtue. Similarly, the definition of education directly refers to virtue inherent in human perfection to which man is destined according to his spiritual nature. In conclusion, peace education requires a close relationship with virtue, a perspective that allows a theoretical redesign of peace education; along these lines, the ethical virtue of humility is operatively proposed as a way of building peace at school.
\end{abstract}

\section{Keywords (Source: Unesco Thesaurus) \\ Teachers; peace education; students; pedagogy; Thomas Aquinas; ethics.}




\section{Educação para a paz: uma reflexão a partir de Tomás de Aquino}

\section{Resumo}

Neste artigo, é tratado sobre o tema da educação para a paz seguindo algumas contribuições teóricas de Tomás de Aquino em sua Suma Teológica. Os objetivos são, por um lado, redefinir a paz sob uma perspectiva filosófica e, por outro, elaborar uma concepção tomista da educação para a paz. O método utilizado é de corte analíticointerpretativo, consistente em averiguar, de forma ordenada, certas passagens da Suma Teológica, integrando-as a uma argumentação original. "Virtude" é o termochave a partir do qual se articulam as principais reflexões deste texto, pois estabelece um vinculo entre as noções de paz e educação, ao mesmo tempo que possibilita uma compreensão diferenciada da educação para a paz. Isso se deve a que a paz, no pensamento de Santo Tomás, refere-se a uma ordem entre as faculdades humanas e as relações interpessoais, que existem somente com dependência da virtude. Além disso, a definição de educação tem uma referência direta à virtude, na qual consiste a perfeição humana à qual o homem está destinado consiste, conforme sua natureza espiritual. Como conclusão, afirma-se que a educação para a paz exige um vínculo intimo com a virtude, perspectiva que permite um redesenho teórico da educação para a paz; nesse sentido, de modo operativo, propõe-se a virtude ética da humildade como via para a construção da paz na escola.

\section{Palavbras-chave (Fonte: tesauro da Unesco)}

Docente; educação para a paz; prática pedagógica; Santo Tomás de Aquino; teoria da educação; virtudes éticas. 
La educación para la paz o la cultura de paz tiene al presente un extenso tratamiento entre las publicaciones académicas que la adoptan como tema de indagación. En todos los análisis sobresale una misma idea de paz asumida explícitamente como núcleo teórico desde el cual se construyen las argumentaciones relativas a la educación para la paz. Esa paz denota un contenido restringido a lo social, en el que, en realidad, no se agota. En efecto, una ulterior consideración de la paz, según Tomás de Aquino, abre a la vista sus dimensiones filosóficas, desde las cuales reconstruir una nueva propuesta de educación para la paz. Este es, a decir verdad, el propósito fundamental a cumplir en las siguientes páginas.

Para eso, se sitúa, en primer lugar, la definición de paz social y el modo en que se aplica en la educación para la paz. Después se detalla la concepción filosófica de paz del Aquinate, cuya clave de interpretación pende de la categoría de orden. Principalmente, el texto al que nos remitimos para su comprensión es la Suma Teológica, de donde se extraerán tres clases de orden: universal, subjetivo e intersubjetivo, reciprocamente dependientes. Estos dos últimos órdenes conectan con la virtud, el término trascendental de la pedagogía tomista, como lo hacen ver Millán-Puelles (1963) y Martínez (2002). El orden subjetivo o de las facultades anímicas y el orden intersubjetivo o de las relaciones interpersonales se establecen en el hombre gracias a la virtud.

La paz es, entonces, para el Aquinate, el orden conseguido en el sujeto y entre los sujetos -como se esclarecerá más adelante-debido a la virtud. Tal apreciación enlaza con la noción tomista de educación, cuya finalidad estriba en conducir al hombre a la perfección por medio de la virtud. Por tanto, la virtud viene a ser aquello en lo que coinciden la paz y la educación, como las entiende santo Tomás. Este será el principal hallazgo teórico de lo que sigue y lo que permitirá concluir que el Aquinate tiene una genuina doctrina de educación para la paz. Finalmente, el último apartado se dirige a volver operativa una de las virtudes más cruciales en las institu- ciones educativas de la que depende, sobremanera, la paz: la humildad.

\section{La paz de la educación para la paz}

Una ojeada rápida a las bases de datos más consultadas da cuenta de que la educación para la paz o la cultura de paz tuvo una viva acogida y abundante bibliografía en los dos últimos decenios del siglo pasado y en los primeros años de este nuevo siglo, en los cuales se teorizaron y formularon vertientes prácticas de aplicación en la escuela (Mayor, 2003). Las razones de ese avance se observan en la tensión mundial impuesta por la Guerra Fría, la proclamación del Año Internacional de la Cultura de la Paz y la creciente escalada terrorista de comienzos del último milenio (Tuvilla, 2004).

En la última década dominan, en Latinoamérica, los trabajos consagrados a analizar fenómenos locales y a poner al alcance de la sociedad civil estrategias de apropiación de la cultura de paz en contextos, comunidades o naciones víctimas de la guerra, la violencia sistemática y los conflictos bélicos (Gómez, 2012; 2015; Cabezudo, 2013; Salazar, 2014; Cerdas, 2015; Rodríguez y Cruz, 2017; Gómez y Gamboa, 2017; Maldonado y Benavides, 2018; Cardozo, Morales y Martínez, 2020). Quizá esto se deba a cierta unanimidad y acuerdo tácito en la academia sobre el significado de la educación para la paz o la cultura de paz. En todo caso, este tema sigue interesando allí donde no se percibe la paz en los ambientes social y escolar.

La paz de la que se habla en la educación para la paz es una paz social. Si bien no ha sido un concepto unívoco en el discurso educativo ni en la investigación acerca de la paz, cabe agrupar las significaciones de la paz en torno a lo social, porque toman como punto de referencia a la sociedad. En definitiva, la paz adopta una doble significación: positiva y negativa (Harto de Vera, 2016). Sin entrar en pormenores, esta última comprende la paz como ausencia de guerra o conflicto armado y aquella lo hace propugnando 
una situación de justicia, equidad y cumplimiento de los derechos humanos, extensibles a todos los ciudadanos. La paz positiva implica la paz negativa y no puede existir donde esta no está presente.

El carácter social de la paz positiva salta a la vista; el de la paz negativa sale a relucir como condición de aquella. Según García, Monserrat y Boqué (2019), la transición de la paz negativa a la paz positiva ha tenido como correlato el curso de las dos guerras mundiales, en donde se popularizó la paz negativa, y la posterior ampliación en los años sesenta de la paz a su versión positiva, debido a los estudios sobre paz que maduraron en ese tiempo. Además, Grasa (1990) vincula a la paz negativa la violencia directa, física o fáctica, acaecida en un territorio o entre Estados, dándose en forma sostenida en el tiempo, mientras que asocia la violencia estructural a la paz positiva. Las estructuras social, económica y política son fuente de violencia toda vez que llevan a que perviva la desigualdad y la injusticia en sociedad. La paz también pasó de ser un ideal perfecto y estático a tener un estatus dinámico, en proceso, siempre de llegada en el porvenir, pero que hay que empezar a construir desde ahora (García et al., 2019).

Como se ve, la paz de la educación para la paz asume un contenido tangible, fácilmente identificable en unas condiciones sociales óptimas para los grupos humanos; como también lo tiene la violencia en lo opuesto. Su objetivo también queda claro al decir que se propone inculcar en los educandos actitudes permanentes y valores de tolerancia, respeto, creatividad para la resolución de conflictos y todos los demás elementos favorables a una convivencia pacífica, con miras a consolidar una ciudadanía promotora de paz (Tuvilla, 2004).

Sin duda, la perspectiva epistemológica que resalta en todo esto procede de las ciencias sociales. Sin embargo, el enriquecido campo semántico de la noción de paz no se agota en esas líneas metodológicas. Tomás de Aquino ofrece una interpretación distinta-filosófica-, con la cual resignificar la paz desde la educación e incluirla dentro de lo que algunos autores llaman pedagogía tomista. Un razonamiento en tal dirección permitirá descubrir en el Aquinate a un exponente de la educación del carácter.

\section{La paz según santo Tomás}

Santo Tomás asimila de san Agustín su concepción de paz. Por tanto, antes de arribar a la paz del Aquinate, habremos de comenzar citando un memorable pasaje de La ciudad de Dios, en el que el obispo de Hipona declara:

Así, la paz del cuerpo es la ordenada complexión de sus partes; y la del alma irracional, la ordenada calma de sus apetencias. La paz del alma racional es la ordenada armonía entre el conocimiento y la acción, y la paz del cuerpo y del alma, la vida bien ordenada y la salud del animal. La paz entre el hombre mortaly Dios es la obediencia ordenada por la fe bajo la ley eterna. Y la paz de los hombres entre sí, su ordenada concordia. La paz de la casa es la ordenada concordia entre los que mandan y los que obedecen en ella, y la paz de la ciudad es la ordenada concordia entre los ciudadanos que gobiernan y los gobernados. La paz de la ciudad celestial es la unión ordenadísima y concordísima para gozar de Dios y a la vez en Dios. Y la paz de todas las cosas, la tranquilidad del orden. Y el orden es la disposición que asigna a las cosas diferentes y a las iguales el lugar que les corresponde. (San Agustin, 1958, pp. 1397-1398)

En este fragmento, transcrito in extenso, sobresalen dos especies de orden que san Agustín refiere a Dios: por un lado, el orden intrínseco al hombre $y$, por el otro, el orden de las interacciones con los demás. En ambos la parte más imperfecta está orientada a la más perfecta. La paz pende de la subordinación de unas cosas a otras, que, vistas como un continuum, integran un orden cuya cima la corana Dios. Esto quiere decir que, en la visión religiosa de san Agustín, la paz del hombre no está más que 
en la unión con Dios. Pero también indica que la paz cuelga del hilo del orden. Una vez este se ha roto, se pierde la paz. En esto reside la clave para comprender lo que es la paz y, consiguientemente, la violencia, desde un punto de vista filosófico.

Con ese doble aspecto, Tomás de Aquino retoma la intuición agustiniana de paz (II-II q. 29 a. 1). Aunque, en el pensar del Aquinate, la paz pertenece propiamente al hombre y derivadamente a los hombres. No es que el hombre esté en paz solo consigo mismo y no necesite de la paz con los otros. Pero esta última paz -que santo Tomás llama concordiapoca influencia tiene sobre el hombre si él mismo no se encuentra en paz en su interior (q. 29 a. ad. 2). En definitiva, la paz auténtica emana de una doble fuente: del interior del hombre y de sus relaciones con los otros. No obstante, la paz con los otros o concordia no acaba con la intranquilidad interior, si persiste el desasosiego; por eso la paz tiene sus raíces más profundas en el corazón del hombre.

¿En qué consiste esa paz del corazón? Para santo Tomás, la paz consiste en la quietud del apetito sensible y racional surgida como efecto de que el hombre alcanza la posesión del bien verdadero. En otras palabras, la paz tiene que ver con un estado interior de serenidad y tranquilidad que el hombre consigue como consecuencia de que las potencias apetitivas no solo desean un mismo bien, sino que llegan a gozar de él sin que ningún obstáculo se lo impida (Irizar y Rodríguez, 2017). Unificar las tendencias apetitivas no solo hace que no se busquen muchas cosas, a causa de un deseo disgregado, sino que se esté más tranquilo con menos o, por mejor decir, con lo esencial.

Santo Tomás ilustra la condición de orden interior al hombre (I q. 95 a. 1) diciendo que el hombre, en su estado de inocencia original, poseía un cierto orden en sus facultades que lo dirigían hacia Dios. Así, la razón estaba sometida a Dios, las facultades irracionales a la razón y el cuerpo al alma. Ese orden intrínseco al hombre le aseguraba la paz del cora- zón, al tener en armonía sus apetitos, destinándolos a un mismo objeto: Dios, en quien se aquieta la búsqueda de la felicidad (I-II q. 3 a. 8). Empero, esa constitución humana original no era natural, sino imperfecta, ya que quedó destruida con el pecado.

Ahora bien, la paz entre los hombres radica en la concordancia de voluntades en un mismo sentir. El componente afectivo de esta paz, que santo Tomás también entiende como amistad, lo remarca con una expresión de Cicerón: "entre amigos hay un mismo querer y un mismo no querer" (II-II q. 29 a. 3). En este pasaje de la Suma, santo Tomás está pensando no en una suerte de relaciones impersonales, casuales o utilitaristas, sino en unas relaciones humanas estrechas, las del tipo de la amistad. La paz entre los hombres no anula la diversidad de opiniones - piénsese, por ejemplo, en la amistad de santo Tomás y san Buenaventura-, pero sí reclama o exige que los hombres expresen entre sí un afecto mutuo.

La importancia de la amistad se hace patente en la civitas. Siguiendo a Aristóteles (2014), santo Tomás comenta que, "por medio de la amistad, parecen conservarse las ciudades" (In VII Ethic. lect. 1, en 2001, p. 450;), con lo cual asemeja amistad y concordia. La concordia hace que coincidan diferentes intereses individuales en el mismo bien de la ciudad (Irizar, 2014), como resultado de la unión entre los individuos, que sobreponen a sí mismos el bien de los demás gracias a la amistad. Esta amistad cívica o política (Irizar, 2014) lleva a la paz entre los hombres, porque la convivencia a que da lugar es una en la que cada quien mira por el bien del otro. Por ende, la paz social está directamente relacionada con la búsqueda y consecución del bien común en la ciudad.

En resumidas cuentas, Tomás de Aquino comparte la noción de paz de san Agustín, a la que ve encarnarse, por así decirlo, en esa doble dimensión relacional del hombre consigo mismo y con los demás. Además, como san Agustín, santo Tomás es un hombre de religión. Por tanto, la paz tiene también para él un fundamento divino. 
En esta concepción de paz destaca el término orden como núcleo fundamental de la definición de paz. Santo Tomás vislumbra un orden universal que estructura a la realidad toda y sostiene (I q. 2 a. 3) que la realidad está organizada conforme a un nivel de jerarquía que asciende de lo menos perfecto a los más perfecto y en el cual todos los seres tienden hacia Dios como a su último fin. El orden universal, entonces, se concreta en que Dios otorgó a cada cosa un fin correspondiente con su esencia y la posibilidad de adherirse a él usando los medios -que Él mismo ideó- disponibles a tal propósito (I-II q.102 a. 1).

Tomás de Aquino denomina a esto providencia y gobierno de Dios sobre el mundo (I q. 22 a. 3). Así, y no obstante la diversidad de las creaturas cuyo origen es Dios (I q.47 a.1 y 2), el mundo se encuentra en armonía "en cuanto que unas cosas están ordenadas a otras" (I q. 47 a. 3) y, de esta manera, manifiestan la unicidad del cosmos. Santo Tomás también dirá en una cuestión anterior de la Suma que "todo lo existente está intimamente ordenado, ya que unas cosas sirven a otras" ( $\mathrm{q}$. 11 a. 3). Ese orden, por el que cada creatura desea lo que le es propio y ocupa el lugar que le toca, permite a santo Tomás afirmar que los seres irracionales también desean la paz en la medida en que el apetito natural de ellos busca aquietarse en el bien al que tienden naturalmente (II-II q. 29 a. 2 ad. 1).

En síntesis, Tomás postula que el orden está constituido en una modalidad dual: por un lado, encuadra "las partes de un todo o de un conjunto entre sí, como las partes de una casa están ordenadas unas con otras"; por otro, guía "las cosas respecto del fin" (In I Ethic. lect. 1). El respeto de este orden forma parte del querer de Dios, pues la voluntad divina quiere lo que hace, aun cuando no tenga necesidad de algo exterior ( q. 19 a. 2 y 3). Como consecuencia, una deducción lógica de las anteriores premisas es que la violencia se opone a la paz por cuanto socava el orden de la realidad instaurado por Dios en la creación. Así se llega a la antítesis de la paz: la violencia.
Caponnetto (2004) y Sánchez (2015) exponen en breves reflexiones el pensamiento de Tomás de Aquino relativo a la violencia. Ambos autores concuerdan en destacar que la violencia, según santo Tomás, tiene tres distintas aproximaciones. De acuerdo con la línea de argumentación seguida hasta ahora, aquí interesa una de ellas: la que dice que la violencia impide a un ser cualquiera alcanzar el fin al que su tendencia natural le inclina (I-II q. 6 a. 5; In Metapys. V, 6, en Tomás de Aquino, 2000). Si la violencia se ejerce contra un individuo inteligente, capaz de elección, se llama involuntaria; si es contra uno irracional, se denomina antinatural. Ello connota que la violencia procede de un agente exterior que obstaculiza la inclinación -voluntaria o natural- a llegar a su fin (In III Ethic. lect. 1). Por ende, la violencia acaba con la paz en cuanto que corrompe el orden de la realidad por el cual cada creatura está en búsqueda de su fin propio.

Con todo, santo Tomás precisa que en el mundo natural unos seres tienen que dejar de existir para el bien del todo, esto es, del universo (I q. 22 a. 2 ad. 2 ; ( q. 49 a. 2). De modo que la violencia hallada aquí no anula el orden universal de la creación, pero sí supone un cierto "desorden" particular para diferentes clases de seres. A decir verdad, el orden universal -al menos el de nuestro planeta-es atacado por la violencia del hombre. Empero, santo Tomás expresa que nada escapa de la providencia divina (l q. 103 a. 8), así que todo cuanto sucede, incluso el mal, es regido por Dios, aun cuando no sea querido por Él. Pegues (2010) sentencia: "es tal el soberano poder de Dios, que utiliza el mal particular subordinándolo a un fin más elevado, para que contribuya al bien universal" (p. 6o). Pero Tomás también advierte que, pese a la primacía del poder de Dios, el hombre con su libertad puede tratar de violar ese plan divino querido para todas las cosas, apartándose del bien que le conviene a su esencia (I q. 103 a. 8 ad. 2).

\section{La educación según santo Tomás}

Tomás de Aquino no tiene, hablando con propiedad, una filosofía de la educación (Martínez, 2002; 
2004) y ni siquiera una definición en forma del término educación (Millán-Puelles, 1958; 1963). Sin embargo, eso no obsta a que se encuentre en la obra del santo una clara referencia a la educación. Los citados filósofos entienden que para el Aquinate la educación es la "conducción y promoción hasta el estado perfecto del hombre en cuanto hombre, que es el estado de virtud" -como se enuncia en comentario de santo Tomás al Libro de las Sentencias de Pedro Lombardo (In Sent. IV, d. 26, q. 1, a. 1, en Martínez, 2002)-. En concordancia con esta formulación, Altrejos asevera que la comprensión de la educación por parte del Aquinate "se mantiene firme" hasta el presente en su fundamentación nuclear, "expresando la esencia de la acción educativa” (2011, p. 26). Cada uno de esos términos de la definición tiene su propio sentido que hace inteligible la idea de educación del Aquinate. Exploremos su significado en aras de captar su singular alcance.

Para empezar, la voz latina educatio, tal como se emplea en distintos textos aquinatenses, posee matices ambiguos que Millán-Puelles (1963) y Martínez (2002) reducen a tres, a saber: nutritio, instructio y disciplina. Por el primero, se alude a la acción de los padres por la cual nutren con alimento al hijo engendrado y le asisten con el cuidado de las cosas materiales. Los otros dos términos tienen una dimensión inmaterial; manifiestan la educación espiritual del alma. En consecuencia, la palabra educatio se usa de manera análoga para denotar, a la vez, una función meramente corpórea, esto es, de sostenimiento del cuerpo, pero, por otro lado, para resaltar un aspecto trascendente o de crecimiento espiritual. Sin embargo, Millán-Puelles y Martínez observan que la educación versa principalmente sobre la conducción espiritual. Ese es el sentido auténtico de la educatio en santo Tomás.

A su vez, Martínez (2002) muestra de forma completa las diversas connotaciones que toman la instructio y la disciplina en fragmentos desiguales del Angélico. Instructio, en primer lugar, designa la formación intelectual o comunicación de la verdad y, en segundo lugar, revela una enseñanza de orden práctico encaminada a realizar el bien. Martínez prueba, en definitiva, que la instructio conserva un vínculo más estrecho con la práctica del bien, ya que el conocimiento intelectual dispone para el libre actuar mediante la prudencia. Disciplina, por su parte, contiene una variedad semántica más amplia: "efecto de educar" y "doctrina que se enseña" (2002, p. 97), "acción de educar la virtud" (p. 99) y "acción de aprender"y "acción de enseñar" (p.101). No obstante, Martínez, como Millán-Puelles, asiente en que la definición real de educatio que propone el Aquinate es la que se registra en In Sent. IV.

Luego de estas precisiones, estamos preparados para examinar lo que santo Tomás concibe por educación. Una exposición eminente de este tema se halla en Millán-Puelles (1963), que, por lo mismo, merece total atención. En el análisis de la definición de educación del Aquinate, Millán-Puelles comienza dilucidando los términos de conducción y promoción. Para el filósofo español, ambos conceptos mientan el fin de la educación o su teleología, que se describe a continuación con las palabras estado perfecto del hombre. La conducción y promoción subrayan el propósito intencional del proceso educativo que pende del educador, a quien se le confía la tarea de dirección del educando, el cual debe asumir o aceptar desde sí mismo dicha acción que se ejerce sobre él.

Ahora bien, en el fin de la educación -"estado perfecto del hombre en cuanto hombre"- aparecen las categorías estado y perfecto a las que MillánPuelles dedica unas aclaraciones. Estado viene de status y stare, que traducen una situación más o menos pasajera o poco permanente; como tal, se contrapone a ser o esse, a lo estable que hay en algo existente. Eso estable es el ser sustancial que recibe un ente con la generación a través de la forma sustancial, pero, como de entrada, no tiene toda la perfección que merece por su esencia, el ente debe alcanzar un estado de ulterior de acabamiento. Precisamente, status implica esa posibilidad de perfeccionamiento que, en el caso del hombre, la educa- 
ción está llamada a conferir. Por perfecto se indica el resultado subyacente al despliegue de la riqueza interior humana, que, por eso mismo, recibe el nombre de humanización. La educación aspira a ello y, por esa razón, no tiene una finalidad particular, sino universal, aplicable a todos los géneros educativos, ya sea técnico, profesional, laboral, etc. Por último, la definición de educación se refiere a la naturaleza humana, a lo que tienen en común los hombres de todas las épocas, sin importar su historia o cultura, y la naturaleza humana es susceptible de educarse en sus facultades o potencias anímicas, que son las que permiten adquirir la virtud.

Con esto llegamos a la conclusión de la definición tomista de educación o al estado de virtud. La virtud perfecciona al hombre porque las potencias del alma, en lo que tienen de operativas, andan tras del fin al que están destinadas y, como dice santo Tomás (I q.5 a.4), todo fin en cuanto tal es un bien; mas el bien comporta perfección. Asimismo, santo Tomás explica que algunas potencias humanas no están determinadas a obrar de tal modo que con sus movimientos siempre aprehendan el fin (I-II Q.5O a. 2 y 9.55 a. 1). Necesitan del plus de la virtud -un modo de ser, en opinión de Aristóteles (2014)- cuya firme disposición las predetermina a unirse con facilidad y deleite a sus objetos específicos (Irizar, 2012). De ahí podrá concluirse que la virtud va estableciendo en el hombre el orden interior, el mismo que se insinuó cuando se dijo que las facultades inferiores a la razón le deben obediencia o sumisión. Pues la racionalidad humana, con la virtud, no solo tiende a dominar sobre los instintos, sino a conciliarlos en torno a ella y a emplearlos en su ayuda.

Después de estas breves consideraciones acerca de la educación en santo Tomás, importa ahora sintetizar de qué manera la virtud introduce orden en las potencias anímicas, con miras a enfatizar que la paz del corazón está asociada con ese orden interior al alma.

Siguiendo al Aquinate, la paz se exterioriza, al igual que la inquietud. Esta última, en efecto, raya en una forma de violencia cuando trasciende al sujeto afectando negativamente a los demás. Este razonamiento resulta importante a la hora de combatir la violencia en los establecimientos educativos y de cultivar actitudes de paz en los estudiantes. Como se ejemplificará, el orden o desorden internos revierten en comportamientos a favor o contrarios a la paz en el sector educativo.

Santo Tomás da a entender (I-II q. 55 a. 2 ad. 1) de qué manera la virtud pone orden en el accionar de las facultades anímicas: "Ahora bien, la virtud hace que la operación sea ordenada. Luego, la misma virtud es una cierta disposición ordenada en el alma, en el sentido de que las potencias están de algún modo ordenadas entre sí y respecto de las potencias exteriores". Ese orden causado por la virtud en las acciones se especifica en una doble vía. Quizás donde más claro se perciba es en la moderación del actuar y del apetito -sensible e intelectual-que, de no sujetarse, acaba inclinándose hacia lo excesivo o lo defectuoso. Porque la virtud, de hecho, implica la tendencia a escoger siempre un punto medio relativo al sujeto (In II Eth. lect. 7). En último término, la virtud marca un orden a la afectividad y a los actos humanos midiéndolos conforme a su deber ser que se conoce a través de la recta ratio (Aristóteles, 2014).

De otro lado, el alma humana también posee orden y es el que existe entre la facultad irracional y la racional (I. q. 77 a. 4 y q. 78 a. 1), que se cumple cuando esta domina sobre aquella por medio de la virtud y endereza al hombre a una vida plenamente humana (Rodríguez, 2010). La cooperación recíproca entre ambas facultades define el orden característico del alma humana. De esta manera, se valida la noción de orden de santo Tomás como disposición hacia el fin y proporción de las partes en un todo, por la virtud. Por lo primero, la virtud facilita la consecución del fin de la acción; por lo segundo, funda una relación equilibrada entre las potencias del alma.

Por el contrario, el vicio y el pecado quiebran ese orden conseguido gracias a la virtud (I-II q. 71 a. 1). 
Este último lo hace en la medida en que desordena el acto privándolo de su auténtico objetivo: el verdadero bien humano, ya que trae corrupción en la naturaleza de algo. Acto seguido (a. 2), santo Tomás esclarece este último punto. Insiste en que el vicio se contrapone a la virtud y recuerda que esta conlleva una disposición favorable a la naturaleza de la cosa, por no faltarle la perfección conveniente a su modo de ser. Muestra después de qué forma el vicio contraría a la virtud. Si la virtud perfecciona la naturaleza del ser y, tratándose del hombre, su naturaleza es racional, el vicio, por tanto, va en detrimento de la racionalidad humana. El vicio supone un menoscabo de la naturaleza del hombre, al impedir un ejercicio óptimo de la razón y alejarla progresivamente de su meta última: la contemplación del bien más elevado.

\section{Humildad y soberbia en la Summa theologiae}

Llegados a este punto, vale la pena no perder de vista el propósito de lo dicho hasta el momento. La reflexión filosófica emprendida ha situado en primera instancia la noción tomista de paz, a la que acompaña, en contraposición, la de violencia. En el fondo, lo que se trae a colación es la concepción de virtud de santo Tomás en relación con su propuesta sobre la educatio, para argumentar que la virtud produce la paz del corazón que se abre a los demás en un cúmulo de relaciones fraternas, mientras que el vicio provoca lo contrario. De ahí una de las razones de santo Tomás para que la educación propenda por la formación de la virtud como meta principal.

El cometido de este apartado se cifra en sugerir una alternativa práctica que conduzca a la adquisición de la humildad como parte de las actitudes de los educandos. Con tal objetivo, va a presentarse lo que santo Tomás expone acerca de dicha virtud y tal vicio en la Suma Teológica. Junto a esto, tendrá que ilustrarse cómo repercute una y otro en la institución educativa. Así las cosas, estará despejado el horizonte para formular una estrategia hacedera en favor del logro de la humildad. Un pensamiento de Simone
Weil ayudará a esa pretensión. Además, no debe olvidarse en todo esto el rol que desempeña el docente.

Una cabal aproximación a lo que es la humildad se avista en la Suma Teológica (II-II q.161 a. 2), donde santo Tomás sitúa dos componentes correlativos de la humildad: "moderar el deseo de la propia excelencia”, en palabras de Forment (1998, p. 187), y tener conocimiento de los defectos propios, que es lo que subyuga las ansias de grandeza. Pieper parafrasea esto último mencionando que la humildad "consiste en que el hombre se tenga por lo que realmente es" (2010, p. 267). Desde luego, más características decisivas añade santo Tomás a la humildad (IIII q. 161), pero basta con lo anotado para la finalidad de este trabajo.

Por otra parte, el Aquinate considera (II-II q. 162 a. 2) que la soberbia es un deseo inmoderado de ser superior o estar por encima de los demás. La malignidad de la soberbia -apunta Tomás- se reconoce en que su peligroso influjo se extiende por igual a vicios y virtudes, bien porque cualquier deseo desordenado oculta tras de sí un afán por escalar en la excelencia (a. 2), o bien porque el muy crecido en virtudes puede ensoberbecerse a causa de ello (a. 2 ad. 3). Forment delata el daño que acarrea la soberbia en el trato con los otros al afirmar que por este vicio se "desprecia y humilla a todos los que juzga inferiores" (1998, p. 179), como también lo hace santo Tomas al insinuar que hay una cuarta especie de soberbia "que tiene lugar cuando uno, despreciando a los demás, desea que todos le miren" (II-II q.162 a.4).

Entre las varias críticas que se le endilgan a la universidad contemporánea, hay una que enlazamos, por analogía, con ese deseo malsano de sobresalir. Las críticas a la universidad pasan por su abandono progresivo de las humanidades como distintivo básico de la formación universitaria. Actualmente, pesan más en los currículos académicos las ciencias técnicas, tecnológicas y experimentales, a las que se valoran en tanto en cuanto proporcionan un bienestar material más inmediato y útil a la so- 
ciedad. A esta clase de educación Nussbaum (2010) la llama educación para la renta. MacIntyre (citado por Giménez, 2012) también exige a la universidad que no eduque solo por réditos económicos o por situar a sus egresados en una mejor posición económica. La realidad es que la educación superior parece haberse fijado como única meta el preparar a los estudiantes para la competitividad laboral, el éxito profesional medible en los ingresos salariales y la productividad tangible en la economía de un país.

Si bien a simple vista este propósito no es, en sí mismo, desdeñable, lo cierto es que la educación acontece en el contexto de la sociedad de consumo, donde no solo se busca tener cosas materiales, sino acumular más y más, en una carrera antagónica con el otro. Girard (citado por Llano, 2009) denunció la violencia a la que induce semejante estilo de conducta, en el que se desea no un objeto en sí mismo, por su valor, sino en cuanto que otro, como yo, también lo quiere. Aunque quepa identificar otros vicios con una actitud como esta -por ejemplo, la codicia-, debemos recordar que santo Tomás los agrupaba en torno a la soberbia, "a la cual puede ordenarse todo cuanto se desea desordenadamente" (II-II q. 162 a. 2). Es que el interés por hacerse notar, de estar en una altura más elevada que la de los demás, no es sino un signo real de la soberbia. La educación superior también cae en esa lógica de encumbramiento personal, no ya solo perceptible en la sociedad, sino también dentro de ella, al crear mentalidades adaptables al mercado donde lo más que importa es el prestigio, la posición social y la ganancia monetaria.

La universidad ha sido cooptada por la estructura económica (Llano, 2009). Así, se malogra la enseñanza de que la profesión está al servicio del bien común, sustituyéndola por otra, cuya funcionalidad consiente en solo estimular competencias indispensables para el trabajo. Asimismo, el individualismo de las ciudades modernas puede ser avivado, sutilmente, por la educación. Ni qué decir de la soberbia cuando asoma como costumbre cotidiana entre los compañeros de estudio. A veces, se constata cierto sectarismo que, en cuanto provee lazos cercanos de amistad es bueno, pero en cuanto fomenta el indiferentismo es malo. La apatía y el rechazo se intercambian con la enemistad y la animadversión en una atmósfera que imposibilita el aprendizaje radical de los valores sociales. Detrás de esto no existen solo cuestiones de identidad grupal o preferencias y gustos encontrados, sino la incapacidad de no tolerar a otros por no sentirse desestimado o inferior. Ahí es cuando surge la soberbia en el compañerismo escolar.

Otro brote de esta misma raíz sale a relucir entre quienes reclaman ocupar el centro de atención, lo cual no se puede hacer sin incurrir en minusvaloraciones del mérito de los otros. Santo Tomás identifica este aspecto con la jactancia o el exceso en el ornato exterior que la humildad reprime (II-II q. 161 a. 2 ad. 4). La apariencia o el cuidado de la imagen con la intención de atraer las miradas -tan común en buena parte de las jóvenes generaciones- recibe un impulso de ese afán por destacar, tan característico en el orgullo. A la vez, el Aquinate observa que la soberbia simula la fortaleza frente a los demás para ganarse su admiración y estima (II-II q. 162 a. 7 ad. 5). Esto ocurre cuando se finge el arrojo que, en verdad, no se tiene, esto es, cuando impera en lo que se hace o se dice un aire de arrogancia o prepotencia que rebaja la dignidad ajena.

Todo esto, sin lugar a duda, desborda en el irrespeto, la forma más elemental de la violencia (Ballesteros, 2009). La grosería, la burla o la dureza verbal, dichas no para ofender directamente a quien se cataloga como rival, sino para ridiculizar al compañero, no persiguen tan solo dejar mal parado al otro, sino autoensalzarse. Pareciera que la propia identidad y aprecio se autoafirmaran, con consistencia, a través de la humillación a los más cercanos. Esa forma sutil de violencia, corriente entre tantos jóvenes, trae secuelas en la autoestima y deshace los fines nobles de la amistad. Así pues, la vanidad aneja a la tendencia de arrogarse una superioridad banal termina por lastimar y dañar a los que están 
en rededor. Además, demuestra que la soberbia lleva al desvarío de la razón, toda vez que la aparta de lo real, de una justa consideración del individuo mismo y de los demás.

\section{Un camino práctico para la humildad en la educación}

En uno de sus escritos más representativos, Weil (1992) examina, desde una perspectiva cristiana, el papel que cumple el estudio en el fortalecimiento de la atención y, por ende, en la preparación a la oración. Pero, dejando de lado estas particularidades, Weil establece dos condiciones para que el estudio favorezca la atención. La primera manda que este se haga por el solo deseo de la verdad, aun cuando no rinda ningún resultado reconocible en el momento; por ejemplo, al no resolver un problema de geometría. Pero Weil también precisa que la inteligencia progresa de un modo misterioso, sin que uno mismo lo perciba. Es que la inteligencia crece en un ámbito espiritual, en el que, por tanto, no se verifica un crecimiento susceptible de medirse de forma cuantificable. La inteligencia se ensancha sin que tengamos una plena conciencia de ello, pero sus efectos se sienten inesperadamente a través de los actos de conocer, cualesquiera que sean. Así es como el estudio, hecho por sí mismo, sin ningún otro interés, más que el de conocimiento, hace progresar la inteligencia sin que haya evidencias de eso y más allá de los logros inmediatamente alcanzados.

En consecuencia, la atención despierta, por medio del estudio, la impresionante capacidad de la inteligencia, que no está limitada a barreras conmensurables, solo bajo la condición de que realmente vayamos tras la verdad. En adición, Weil (1992) postula una segunda exigencia en la ampliación de la atención. Tiene que ver ella con la tenacidad, más aún, la perseverancia, por no rehuir la tarea de juzgar los porqués de los fracasos en el estudio. Las deficiencias ahí encontradas, que comúnmente se conocen en las calificaciones, debieran importar y suscitar una aguda reflexión, como cree Weil, si en adelante se planea evitar los obstáculos que atascan el trabajo académico y si se quiere alcanzar la humildad. En caso de no prestar cuidado a los errores cometidos en las labores del estudio, difícilmente van a poderse remediar y, así, lo más seguro que llegue sean nuevos yerros. Pero si se los atiende, brota la humildad como parte del reconocimiento de la propia mediocridad con que se han manejado los deberes escolares (Weil, 1992).

Esta segunda condición adquiere un cauce positivo al cual seguir, en orden a establecer un camino práctico para la humildad en la educación. Si el remedio a la soberbia de muchas de las actitudes manifiestas en el comportamiento estudiantil está en la humildad, he ahí una puesta en concreto para su adquisición. No se trata tan solo de amonestaciones o consejos consabidos para centrarse en las falencias del estudio. Se trata, más bien, de una pedagogía asociada con la calificación. La firmeza, no injusticia, en la evaluación es una alternativa, tal vez la mejor, con la que cuenta el profesor para encauzar a la humildad a los alumnos.

Si en vez de escucharse las quejas y los reclamos de los jóvenes al conocer sus bajas notas, más bien los profesores supieran sobrellevar con paciencia esas inconformidades y darles un nuevo sentido, se pondría en marcha, a través de esa circunstancia, un episodio único de formación. Las más de las veces, o los estudiantes están preocupados por aprobar, sin tantos sobresalientes, o descuidan las sugerencias del maestro a sus entregas. El profesor tendría que, como pedagogo, conducirlos por entre el contenido de las entregas hasta descubrirles sus problemas, sin ceder a las presiones de recambio de nota o a rebajar los criterios de evaluación, y menos a la tentación de ahorrarse las correcciones. Ciertamente, no todos parecieran necesitar de las observaciones del docente ni tampoco tendrían por qué enfatizarse ante resultados negativos, pero el hacerlas trae buenos efectos.

Por supuesto, como casi siempre es poco probable llevar a cabo una retroalimentación particulari- 
zada con cada estudiante, el docente debería ocuparse en esos casos de englobar con sus comentarios los aciertos y desaciertos vistos en las entregas. Quizá se piense que esto poca mella haga en los estudiantes, y tienen razón quienes piensan así. Weil (1992) reconocía que de natural no estamos bien dispuestos a analizar aquello en lo que fallamos, por lo que incluso a los académicos más experimentados no les salga espontáneo autorrevisarse. Sin embargo, ser impreciso al asignar una nota -máxime cuando se es constante-es algo de lo que se enteran los jóvenes, y las sospechas que se levantan van en detrimento de la autoridad y credibilidad docente. Por eso, lo primero es ser justo en la calificación, lo cual incluye tener que dar razones de la misma. De esta manera, los estudiantes llegarán poco a poco a percatarse de sus propias limitaciones o deficiencias en lo académico, aspecto en lo que concuerda la humildad.

En general, los estudiantes están preocupados de sus notas y piden aclaraciones cuando no están contentos con las que obtienen; algunas veces movidos por una recta intención de aprender, otras por puras cuestiones pragmáticas. Sea como fuere, se está presentando una oportunidad especial para animar, ser benevolente y no dejar de corregir los fallos. Ser laxos no es hacerles un favor a los alumnos, es volverlos menos luchadores. La labor docente tiene también que acompañar el progreso humano o moral de los estudiantes, porque la educación, en sentido propio, en una reminiscencia tomista, es "la ayuda que una persona presta a otra para que se perfeccione" (Forment, 1997, p. 207). Por esto, las ocasiones de diálogo sobre la nota son un medio adecuado para favorecer dicho progreso en la perspectiva trazada hasta ahora.

En todo esto resalta la función del profesor. Ante todo, su integridad moral y conciencia de que su actuar no se reduce a mera instrucción, sino que abarca el oficio de educere, de extraer lo mejor de los educandos. Por tanto, determinar qué tanto ha aprendido un estudiante no es la única ni la principal ocupación de un docente. También, aunque no lo compruebe ni obtenga resultados inmediatos (Altrejos, 2005), debe ayudar en la formación del carácter de los jóvenes a través de la virtud. En realidad, él mismo debe poseer un cúmulo de virtudes, porque, sabemos, la trasmisión de la virtud no se logra por lo mucho que se diga, sino por la reciedumbre de una personalidad madura que irradia en su comportamiento las virtudes morales. Así que el profesor ha de ser, para sus estudiantes, un estímulo para la virtud, y una de las opciones más prácticas con que cuenta para introducirlos en la humildad es concientizarlos de sus errores en el trabajo académico, porque esta virtud implica el conocimiento de los propios límites y faltas, así como el esfuerzo por superarlos.

\section{Conclusión}

La paz de corte filosófico, de la que habla santo Tomás, tiene connotaciones que no se perciben en la paz de la educación para la paz. No diremos que más ricas, pero sí que se entrelazan en un sistema pedagógico coherente del que Millán-Puelles (1963) y Martínez (2002) han dado cuenta, entresacándolo de la obra del Aquinate. La pieza fundamental es la virtud, con la cual edificar la paz del alma y la paz social desde la educación. Virtud y paz se apoyan mutuamente en el pensamiento de santo Tomás. Sin virtudes personales no hay paz posible. Por eso urge enseñar o comunicar la virtud en las instituciones educativas, a pesar de que Aristóteles (2014) ya hubiera advertido con acierto que no existen recetas concretas de apropiación de la virtud. No puede haberlas, porque la formación del ethos personal recae en la subjetividad, es decir, en la libertad e intención individuales, a donde nadie puede extender su influjo más que el mismo sujeto.

Empero, la importancia de la virtud no permite desistir del afán por enseñarla. Ciertamente, hay que idear posibles vías de acceso a la virtud en la educación formal, sin nunca pensar que todo va a marchar bien a partir de meras estrategias didácti- 
cas. En el último apartado de este texto se trató de ofrecer una alternativa de estas características con el propósito de sugerir un modo de asimilación de la humildad para los estudiantes. El papel del profesor es clave, aunque no pueda garantizar una apropiación efectiva de la virtud como lo hace con el conocimiento. Más propuestas de este estilo, de fomento de la virtud, podrían implementarse en la escuela, porque todo cuanto sucede en los recintos educativos puede reorientarse a la virtud. Así que bien valdría la pena un estudio del sistema de virtudes como lo presenta santo Tomás, conectándolo con la educación. Finalmente, no está demás decir que la pedagogía tomista constituye un modelo teórico sólido cuyas aportaciones encuadran en el movimiento de educación del carácter (Bernal, González y Concepción, 2015), tan emparentado con la virtud como la misma pedagogía tomista.

\section{Referencias}

Altrejos, F. (2005). El ethos docente: una propuesta deontológica. En F. Altrejos, J. Ibáñez-Martín, J. Jordán y G. Jover (eds.), Ética docente (pp. 89-118). Barcelona: Ariel.

Altrejos, F. (2011). Filosofía de la educación (3 ed.). Pamplona: Eunsa. Recuperado de: https://elibro.net/es/ereader/ usta/47101? page $=26$

Aristóteles (2014). Ética a Nicómaco (J. Pallí Bonet, trad.). Madrid: Gredos.

Ballesteros, J. (2009). Repensarla paz. Pamplona: Eunsa. Recuperado de:https://elibro.net/es/ereader/usta/55162?page=11

Bernal, A., González-Torres, M. y Concepción, N. (2015). La educación del carácter. Perspectivas internacionales. Participación Educativa, 4(6), 35-45.

Caponnetto, M. (2004). Una reflexión filosófica acerca de la violencia. [Ponencia], XVII Congreso Argentino de Logoterapia, Buenos Aires, Argentina, 2-4 de septiembre. Recuperado de: https://juangabrielravasi.wordpress.com/una-reflexion-filosofica-acerca-de-la-violencia/

Cabezudo, A. (2013). Acerca de una educación para la paz, los derechos humanos y el desarme: desafío pedagógico de nuestro tiempo. Educação, 36(1), 44-49.

Cardozo R., A., Morales C., A. y Martínez S., P. (2020). Construcción de paz y ciudadanía en la Educación Secundaria y Media en Colombia. Educação e Pesquisa, 46. DOI: https://doi.org/10.159o/s1678-4634202046214753

Cerdas-Agüero, E. (2015). Desafíos de la educación para la paz hacia la construcción de una cultura de paz. Revista Electrónica Educare, 19(2), 135-154. DOI: https://doi.org/10.15359/ree.19-2.9

Forment, E. (1997). El profesor católico del siglo XXI. Espiritu. Cuadernos del Instituto Filosófico de Balmesiana, 46(116), 205-222. 
Forment, E. (1998). Persona y valor en santo Tomás. Revista Española de Filosofía Medieval, 5, 171-19o. DOI: https:// doi.org/10.21071/refime.v5i.969o

García-Raga, L, Monserrat, A. y Boqué Torremorell, M. C. (2019). La educación para la paz en las políticas educativas. Un balance histórico y desafíos de futuro. Social and Education History, 8(3), 298-323. DOI: https://doi. org/10.17583/hse.2019.4164

Grasa, R. (1990). Educación para la paz: divulgación de los resultados de la investigación para la paz. Pedagogía Social. Revista Interuniversitaria, 5, 96-165.

Giménez A., J. (2012). La universidad en el proyecto sapiencial de Alasdair MacIntyre. Cuadernos de Filosofía. Excerpta et Dissertationibus in Philosophia, 22, 375-465.

Gómez A., A. (2012). Educación para la paz en el sistema educativo de El Salvador. Ra Ximhai, 8(2), 93-126. DOI: https://doi.org/10.35197/rx.08.01.e.2012.04.ag

Gómez A., A. (2015). Una apuesta educativa para América Latina: educación para la paz. Revista Latinoamericana de Estudios Educativos, 45(1), 17-62.

Gómez A., J. y Gamboa S., A. (2017). Educación para la paz en diversos contextos educativos en Colombia. Revista Interamericana de Investigación, Educación y Pedagogía, 10(2), 233-248. DOI: https://doi.org/10.15332/s1657$107 X .2017 .0002 .14$

Harto de Vera, F. (2016). La construcción del concepto de paz: paz negativa, paz positiva y paz imperfecta. Cuadernos de Estrategia, 183, 119-146.

Irizar, L. B. (2012). La dimensión ética de la vida intelectual. En L. B. Irizar, G. Zanotti y S. L. Brock (eds.), En la era de la cienciometría: una antropología de la investigación científica (pp. 145-171). Medellín: Universidad Pontificia Bolivariana.

Irizar, L. B. (2014). Humanismo cívico: Una invitación a repensar la democracia (3 ed). Bogotá: San Pablo.

Irizar, L. B.y Rodríguez C., C. (2017). Sabiduría y paz. Explorando sus conexiones íntimas desde Tomás de Aquino. En L. B. Irizar (ed.), La sabiduría en Tomás de Aquino. Inspiración y reflexión: perspectivas filosóficas y teológicas (pp. 107-134). Bogotá: Universidad Sergio Arboleda.

Llano, A. (2009). Cultura y pasión. Pamplona: Eunsa. https://elibro.net/es/ereader/usta/46980?page=171

Maldonado M., B. y Benavides E., K. (2018). Educar para la paz: una dimensión de la responsabilidad social universitaria. Ciencias Administrativas, 12, 13-26. DOI: https://doi.org/10.24215/23143738eo24

Martínez G., E. (2002). Persona y educación en santo Tomás de Aquino. Madrid: Fundación Universitaria Española. Martínez G., E. (2004). Ser y educar. Fundamentos de pedagogía tomista. Bogotá: Universidad Santo Tomás.

Mayor Z., F. (2003). Educación para la paz. Educación XX1, 6, 17-24. DOI: https://doi.org/10.5944/educxx1.6.0.350 
ISSN 0123-1294 | e-ISSN 2027-5358 | Educ.Educ. Vol. 24. No. 2 | Mayo-julio de 2021 | pp. 181-196

Universidad de La Sabana | Facultad de Educación

Millán-Puelles, A. (1958). Concepto de educación en Santo Tomás. Revista Española de Pedagogía, 16(64), 359-382. Recuperado de: https://revistadepedagogia.org/wp-content/uploads/2018/o5/1ConceptoDeEducacionEn SantoTomas.pdf

Millán-Puelles, A. (1963). La formación de la personalidad humana (2 ed.). Madrid: Rialp.

Nussbaum, M. (2010). Sin fines de lucro. Por qué la democracia necesita de las humanidades (M V. Rodil, trad.). Madrid: Katz. DOI: https://doi.org/10.2307/j.ctvndv6oc

Pegues, T. (2010). Catecismo de la Suma Teológico de Santo Tomás Aquino para todos. México: Éxodo. https:// elibro.net/es/ereader/usta/130421?page $=61$

Pieper, J. (2010). Las virtudes fundamentales (3 ed.). Madrid: Rialp.

Rodríguez, Y. y Cruz T., N. (2017). La educación para la paz y los derechos humanos: Una mirada desde Cuba. Revista Electrónica en Educación y Pedagogía, 1(1), 91-105.

Rodríguez L., A. (2010). Ética (6 ed.). Pamplona: Eunsa.

Salazar M., I. (2014). Educación para la paz y la convivencia escolar en el Estado de México. Ra Ximhai, 10(2), 293312. DOI: https://doi.org/10.35197/rx.10.02.e.2014.12.is

Sánchez de L., H. (2015). Notas sobre la violencia a la luz del pensamiento tomista. Anales de la Academia Nacional de Ciencias Morales y Politicas. Recuperado de: https://www.ancmyp.org.ar/user/FILES/Sanchez-deLoria.I.15-2.pdf

San Agustín (1958). Obras de san Agustín. La ciudad de Dios (t. XVII). Madrid: Biblioteca de Autores Cristianos .

Tomás de Aquino (2001). Suma de Teología (4 ed.). Madrid: Biblioteca de Autores Cristianos.

Tomás de Aquino (2000). Comentario al libro V de la Metafísica de Aristóteles (J. Morán, trad.). Cuadernos de Anuario Filosófico. Serie Universitaria, 112. Recuperado de: https://dadun.unav.edu/bitstream/10171/4023/3/112.pdf

Tomás de Aquino (2001). Comentario a la Ética a Nicómaco de Aristóteles (2 ed.) (A. Mallea, trad.). Pamplona: Eunsa.

Tuvilla, J. (2004). Cultura de paz: fundamentos y claves educativas. Bilbao: Desclée de Brouwer. Recuperado de: https://elibro.net/es/ereader/usta/47732?page=1

Weil, S. (1992). Waiting for God (E. Craufurd, trad.). Perennial Library, Internet Archive. 